\title{
Peripheral visual field defects after macular hole surgery: a complication with decreasing incidence
}

\author{
Carolin A Gass, Christos Haritoglou, Elisabeth M Messmer, Markus Schaumberger, \\ Anselm Kampik
}

\begin{abstract}
Aim-To prospectively evaluate peripheral visual fields after vitrectomy for idiopathic macular holes.

Methods-Goldmann perimetry was performed in 105 patients before, as well as 6 weeks and 12 months after macular hole surgery.

Results-Only one patient $(<1 \%)$ with a stage III macular hole developed an asymptomatic postoperative visual field defect. The scotoma was wedge-shaped, peripherally located in the temporal quadrant, and remained unchanged during the following 12 months.

Conclusion-Peripheral visual field defects after macular hole surgery can be a complication of very low incidence. A rather low pressure set during air-fluid exchange as well as special aspects of the surgical technique may be responsible for this low incidence of peripheral visual field defects.
\end{abstract}

(Br F Ophthalmol 2001;85:549-551)

Visual field defects after pars plana vitrectomy for full thickness, idiopathic macular hole were first documented in 1995 by Melberg and Thomas. ${ }^{1}$ Since then, this complication has been reported in a number of other studies. ${ }^{2-14}$ Rates as high as $70 \%$ have been reported. ${ }^{3}$ The underlying pathogenesis of visual field defects after macular hole surgery is currently in debate. The purpose of this study was to prospectively analyse the incidence of this complication in our patients and, based on these results, to discuss possible underlying mechanisms.

Department of

Ophthalmology,

Ludwig-Maximilians-

University,

Mathildenstrasse 8, D-80336 Munich,

Germany

C A Gass

C Haritoglou

E M Messmer

M Schaumberger

A Kampik

Correspondence to:

Carolin A Gass

carolin.gass@

ak-i.med.uni-muenchen.de

or Anselm Kampik

akampik@

ak-i.med.uni-muenchen.de

Accepted for publication

14 December 2000

\section{Patients and methods}

A total of 105 eyes of 105 consecutive patients who underwent surgery for idiopathic full thickness macular hole between April 1998 and January 2000 were prospectively evaluated. Each macular hole was graded using the classification proposed by Gass. ${ }^{15}$ Patients with post-traumatic holes, glaucoma, and diabetic retinopathy were not included. Clinical examination before, 6 weeks, and 12 months after vitrectomy included best corrected visual acuity, applanation tonometry, fundus examination with a 78 dioptre lens, fundus stereo photographs, and Goldmann kinetic perimetry performed by well trained technicians. As visual field defects after macular hole surgery are usually described to be deep and located peripherally, preoperative visual field testing included the stimulus size $\mathrm{I}_{4}, \mathrm{III}_{4}$, and $\mathrm{V}_{4}$ to screen for major or deep scotomas. Postoperative perimetry additionally offered the objects $\mathrm{V}_{4}, \mathrm{I}_{4}, \mathrm{I}_{3}$ to rule out eventual relative scotomas. Vitrectomy was performed by four vitreoretinal surgeons with the patient under local anaesthesia. The surgical technique was similar, but possibly different in some specific aspects from those reported previously. ${ }^{16}{ }^{17}$ The surgical technique, ${ }^{18} 19$ included the following principles. (1) For stage II and III idiopathic macular holes, posterior hyaloid detachment was achieved only by high suction around the optic nerve head using the vitrector instrument. (2) In all cases the vitreous was removed including the detached posterior hyaloid up to the periphery without an attempt to remove the far peripheral vitreous. Unless peripheral retinal pathology prompted an intervention the vitreous base remained untouched. (3) Meticulous removal of eventual epiretinal membranes around the fovea always followed by removal of the inner limiting membrane (in this series without the use of indocyanine green staining) was achieved as a rule (and verified by electron microscopy in selected cases not reported in this study ${ }^{21}$ ). (4) Air-fluid exchange through an extrusion cannula over the optic nerve head. The same instrument was also used to remove any subretinal fluid through the macular hole. No adjuvants were used. (5) Finally, a gas mixture $\left(15 \%\right.$ hexafluoroethane $\left.\left(\mathrm{C}_{2} \mathrm{~F}_{6}\right)\right)$ was substituted for the air in the vitreous cavity. This was achieved by the injection of about $25 \mathrm{ml}$ of the $15 \%$ air- $\mathrm{C}_{2} \mathrm{~F}_{6}$ mixture after closure of the superior scleral incisions. At the same time the pressure at the Grieshaber air pump was set at $35 \mathrm{~mm} \mathrm{Hg}$. Immediately after this injection the inferior scleral incision with the infusion cannula hooked to the air pump was closed. With this technique the air flow through the eye was limited to a very short period of time. Postoperatively, prone positioning was encouraged for 5 days.

\section{Results}

Of 105 patients (105 eyes) involved in this study 82 were female and 23 were male. The mean age was 67.5 years (50-80 years). Included were eight stage II, 82 stage III, and 15 stage IV idiopathic macular holes preoperatively. The mean follow up was 8 months (range 1.5-16 months). Postoperatively, all 105 patients were examined 6 weeks and 41 patients 12 months after vitrectomy, including Goldmann perimetry. Closure of the macular hole could be achieved in 92 eyes $(88 \%)$ by one operation. Ten patients (out of 13 patients with persisting macular hole) underwent a second 

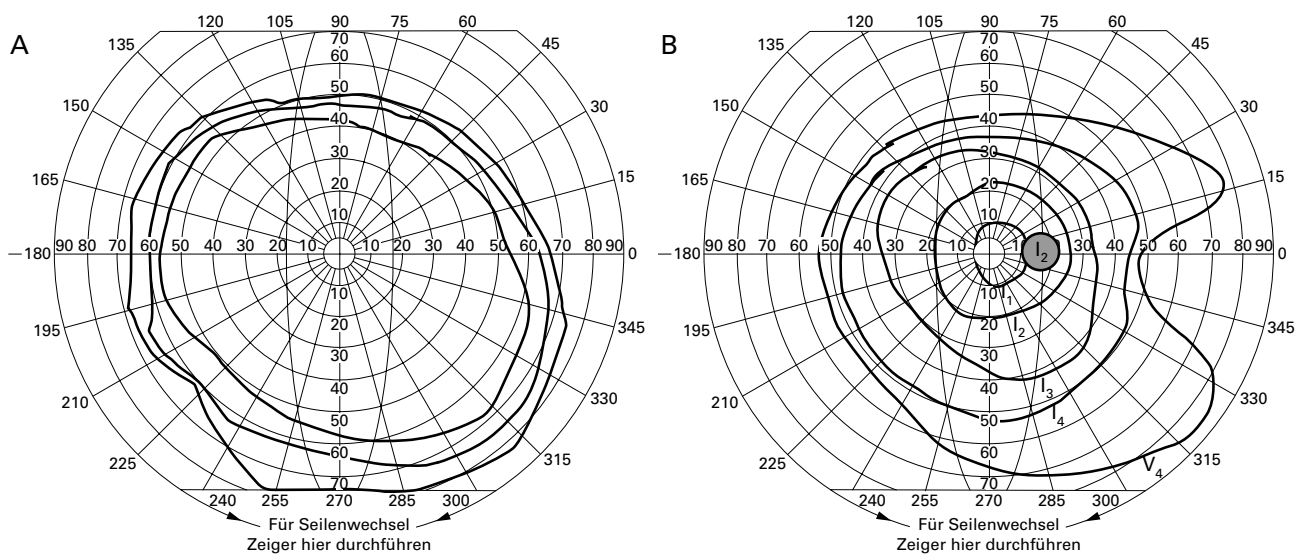

Figure 1 (A) Preoperative and (B) postoperative Goldmann perimetry of the only patient developing visual field defect after macular hole surgery.

operation, leaving only two macular holes unclosed (overall closure rate 95\%). Preoperative peripheral visual fields were normal in 104 patients. One patient, who had a history of stroke, showed a homonymous visual field defect preoperatively and postoperatively. Comparison of preoperative and postoperative visual fields of all 105 patients revealed a new postoperative visual field defect only in one patient with a stage III macular hole. This asymptomatic defect was dense, wedgeshaped, peripherally located in the temporal quadrant (Fig 1), and remained unchanged during the following 12 months.

\section{Discussion}

The pathomechanism of visual field defects after macular hole surgery is still in debate. Various hypotheses have been proposed (see Table 1). Current controversies focus particularly on the following two: (1) mechanical indirect trauma to the peripapillary retina, (2) dehydration injury of the retinal nerve fibre layer. Traction on the peripapillary region during posterior vitreous peeling is common since the cortical vitreous is frequently tightly adherent at the peripapillary retina. ${ }^{22}$ This could potentially cause shearing damage to the optic nerve head, retinal arterioles, or nerve fibre layer. Cullinane and Cleary ${ }^{4}$ recently published a series of 102 consecutive eyes that had undergone vitrectomy for idiopathic stage II and III macular holes. The authors report a significantly lower incidence of postoperative scotomas in patients where no attempt was made to separate the posterior hyaloid from the optic disc compared with those patients with complete posterior vitreous peeling. In our series, however, although complete posterior cortical vitreous peeling was performed, the incidence of postoperative visual field defects is less than $1 \%$, indicating that the above

Table 1 Possible mechanisms for peripheral visual field defects after macular hole surgery

Indirect, mechanical trauma to the peripapillary region ${ }^{124-814}$

Direct, mechanical trauma to the optic disc ${ }^{18}$

Phototoxic effects from exposure to the intraocular fibreoptic illuminators ${ }^{2} 12$

Dehydration injury during air-fluid exchange $\mathrm{e}^{10} 13$

Mechanical or toxic effects of the gas bubble 23712

Retinal or ciliary artery occlusion ${ }^{212} 14$

Glaucomatous damage from elevated postoperative pressure ${ }^{2811}$ mentioned traction theory does not sufficiently explain their pathogenesis. Moreover, potential shearing damage would preferably affect the superficial portion of the nerve fibre layer or its blood supply. Since the course of axons through the retina and optic nerve head is such that nerve fibres of the central retina are located more superficial in the nerve fibre layer than are nerve fibres from more peripherally positioned retina, ${ }^{2324}$ one would rather expect visual field defects adjacent to the blind spot than, as usually described, located in the periphery. An additional argument to weaken a traction hypothesis is the fact that postoperative visual field defects have also been reported in stage IV macular holes with already detached vitreous. $^{271112}$

Dehydration injury to the retina during air-fluid exchange as a possible cause of visual field defects was first discussed by Welch. ${ }^{13}$ Recently Ohji et $a l^{10}$ noticed that the incidence of visual field defects could be reduced from $23 \%$ to $10 \%$ by passing air through water before being injected into the eye (personal communication). In our series the incidence of postoperative visual field loss was less than $1 \%$ although the air was not humidified before being injected into the eye. Hence, dehydration injury alone does not seem to explain postoperative visual field loss completely. Hydrating the air, however, has another known effect: the pressure during air-fluid exchange is lowered proportional to the height of the water column. This may explain the results observed by Ohji et al whose air insufflator during air-fluid exchange was set at $60 \mathrm{~mm} \mathrm{Hg}$, which seems relatively high compared with our pressure set at $35 \mathrm{~mm} \mathrm{Hg}$. We conclude that especially this low setting of the air pressure at $35 \mathrm{~mm} \mathrm{Hg}$ is one potential mechanical reason for a lower incidence of visual field defects after macular hole surgery. Findings of Murata et $a l^{9}$ support this hypothesis: by lowering the air pressure during air-fluid exchange from $50-30 \mathrm{~mm} \mathrm{Hg}$, the incidence of postoperative scotomas was reduced significantly from $30 \%$ to $0 \%$. Another clinical trial confirming this theory was recently presented by Ishigooka et $a l^{6}$ : at a pressure set of $50 \mathrm{~mm} \mathrm{Hg}$ during air-fluid exchange the incidence of postoperative visual 
field defects did not show any distinct differences between eyes with or without humidified air. At air pressures of less than $30 \mathrm{~mm} \mathrm{Hg}$, however, the occurrence of visual field defects decreased from $18.8 \%$ to $1.2 \%$, regardless of the air humidity. On the other hand, $35 \mathrm{~mm} \mathrm{Hg}$ was the standard infusion setting used at the institutions in Boldt et al, ${ }^{2}$ Hutton et al, ${ }^{7}$ Pendergast and McCuen, ${ }^{12}$ (personal communication). Hence, a lower pressure setting during air-fluid exchange alone does not completely explain the variable rates of visual field defects after macular hole surgery.

Therefore, surgical technique as such has to be evaluated as another mechanism for the occurrence of field defects. The technique used in this series might be different from previous descriptions. The vitreous including the detached posterior hyaloid in this series was purposely not completely removed. This fact in combination with the lower pressure set at the air pump leads to a decreased flow of air through the vitreous cavity during air-fluid exchange by an eventual partial obstruction of the scleral openings. Less flow of air decreases the possibility of a dehydration injury. Another factor is the duration of air flow during air-fluid or air-gas exchange. This time was kept relatively short, which is no longer than 10-15 minutes at maximum. Again this fact limits the possibilities of elevated intraocular pressure and dehydration of the retina. In summary, with the described specified surgical technique, peripheral visual field defects after macular hole surgery are a rare complication with decreased incidence compared with other studies.

1 Melberg NS, Thomas MA. Visual field loss after pars plana vitrectomy with air/fluid exchange. Am $\mathcal{F}$ Ophthalmol 1995;120:386-8

2 Boldt HC, Munden PM, Folk JC, et al. Visual field defects after macular hole surgery. Am $\mathcal{F}$ Ophthalmol 1996;122 $371-81$.
3 Bopp S, Lucke K, Hille U. Peripheral visual field loss after vopp S, Lucke K, Hille U. Peripheral visual field loss after vitreous surgery for macular
Ophthalmol 1997;235:362-71.

4 Cullinane AB, Cleary PE. Prevention of visual field defects after macular hole surgery. Br f Ophthalmol 2000;84:372-7.

5 Ezra E, Arden GB, Riordan-Eva P, et al. Visual field loss folowing vitrectomy for stage 2 and 3 macular holes. $\mathrm{BrF}$ Ophthalmol 1996;80:519-25.

6 Ishigooka H, Mawatari Y, Ogawa K, et al. Prophylactic trials for prevention of visual field defects after vitrectomy for macular hole. Invest Ophthalmol Vis Sci 2000;41(4, suppl):S343.7.

7 Hutton WL, Fuller DG, Snyder WB, et al. Visual field defects after macular hole surgery. A new finding. Ophthalmology 1996;103:2152-9.

8 Kerrison JB, Haller JA, Elman M, et al. Visual field loss following vitreous surgery. Arch Ophthalmol 1996;114:564-9.

9 Murata Y, Hirata A, Yonemura N, et al. Visual field defect following vitrectomy for idiopathic macular hole. Invest Ophthalmol Vis Sci 1999;40(4, suppl):S35.

10 Ohji M, Nao-IN, Saito Y, et al. Prevention of visual field defect after macular hole surgery by passing air used for fluid-air exchange through water. $A m$ f Ophthalmol 1999;127:62-6.

11 Paques M, Massin P, Santiago PY, et al. Visual field loss after vitrectomy for full-thickness macular holes. Am f Ophthalmol 1997;124:88-94.

12 Pendergast SD, McCuen BW. Visual field loss after macular hole surgery. Ophthalmology 1996;103:1069-77.

13 Welch JC. Dehydration injury as a possible cause of visual field defect after pars plana vitrectomy for macular hole. Am $\mathcal{F}$ Ophthalmol 1997;124:698-9.

14 Yan H, Dhurjon L, Chow DR, et al. Visual field defect after pars plana vitrectomy. Ophthalmology 1998;105:1612-6.

15 Gass JDM. Idiopathic senile macular hole: its early stages and pathogenesis. Arch Ophthalmol 1988;106:629-39.

16 Kelly NE, Wendel RT. Vitreous surgery for idiopathic macular holes: results of a pilot study. Arch Ophthalmol 1991;109:654-9.

17 Wendel RT, Patel AC, Kelly NE, et al. Vitreous surgery for macular holes. Ophthalmology 1993;100:1671-6.

18 Liesenhoff O, Messmer EM, Pulur A, et al. Operative Behandlung durchgreifender Makulaforamina. Ophthalmologe 1996;93:655-9.

19 Kampik A. Macular holes-a diagnostic and therapeutic enigma? Br f Ophthalmol 1998;82:338.

20 Heidenkummer HP, Kampik A. Morphologische Analyse epiretinaler Membranen bei chirurgisch behandelten idiopathischen Makulaforamina. Ophthalmologe 1996;93:6759 .

21 Messmer EM, Heidenkummer HP, Kampik A. Ultrastructure of epiretinal membranes associated with macular
holes. Graefes Arch Clin Exp Ophthalmol 1998;236:248-54.

22 Sebag J. Structure of the vitreous. In: Sebag J, ed. The vitreous: structure, function, and pathobiology. New York: vitreous: structure, function,

23 Minckler DS. The organization of nerve fiber bundles in the primate optic nerve head. Arch Ophthalmol 1980;98:16306.

24 Radius RL, Anderson DR. The course of axons through the retina and optic nerve head. Arch Ophthalmol 1979;97: 1154-8. 